\title{
Anticontractile effect of perivascular adipose tissue and leptin are reduced in hypertension
}

\author{
Beatriz Gálvez-Prieto ${ }^{1 \dagger}$, Beatriz Somoza ${ }^{*}{ }^{\dagger}$, Marta Gil-Ortega ${ }^{2}$, Concha F. García-Prieto ${ }^{2}$, \\ Ana I. de las Heras ${ }^{1}$, M. Carmen González ${ }^{3}$, Silvia Arribas ${ }^{3}$, Isabel Aranguez ${ }^{4}$, Juliane Bolbrinker ${ }^{5}$, \\ Reinhold Kreutz ${ }^{5}$, Mariano Ruiz-Gayo ${ }^{2}$ and Maria S. Fernández-Alfonso ${ }^{1}$ \\ 1 Instituto Pluridisciplinar, Facultad de Farmacia, Universidad Complutense de Madrid, Madrid, Spain \\ ${ }^{2}$ Laboratorio de Farmacología, Departamento de Ciencias Farmacéuticas y de la Alimentación, Facultad de Farmacia, Universidad CEU-San Pablo, Madrid, Spain \\ ${ }^{3}$ Departamento de Fisiología, Facultad de Medicina, Universidad Autónoma de Madrid, Madrid, Spain \\ ${ }^{4}$ Departamento de Bioquímica, Facultad de Farmacia, Universidad Complutense de Madrid, Madrid, Spain \\ ${ }^{5}$ Department of Clinical Pharmacology and Toxicology, Charité Centrum für Therapieforschung, Berlin, Germany
}

\section{Edited by:}

Concepción Peiró, Universidad

Autonoma de Madrid, Spain

Reviewed by:

Carmen Martínez, Université

d'Angers, France

Christine Ivashchenko,

GlaxoSmithKline, USA

*Correspondence:

Beatriz Somoza, Laboratorio de Farmacología, Departamento de

Ciencias Farmacéuticas y de la Alimentación, Facultad de Farmacia, Universidad CEU-San Pablo, Cra de Bodilla del Monte, Km 5.300, 28668 Madrid, Spain.

e-mail: bsomoza.fcex@ceu.es

${ }^{\dagger}$ Beatriz Gálvez-Prieto and Beatriz Somoza have contributed equally to this work.
Leptin causes vasodilatation both by endothelium-dependent and -independent mechanisms. Leptin is synthesized by perivascular adipose tissue (PVAT). The hypothesis of this study is that a decrease of leptin production in PVAT of spontaneously hypertensive rats (SHR) might contribute to a diminished paracrine anticontractile effect of the hormone. We have determined in aorta from Wistar-Kyoto (WKY) and SHR (i) leptin mRNA and protein levels in PVAT, (ii) the effect of leptin and PVAT on contractile responses, and (iii) leptininduced relaxation and nitric oxide (NO) production. Leptin mRNA and protein expression were significantly lower in PVAT from SHR. Concentration-response curves to angiotensin II were significantly blunted in presence of PVAT as well as by exogenous leptin $\left(10^{-9} \mathrm{M}\right)$ only in WKY. This anticontractile effect was endothelium-dependent. Vasodilatation induced by leptin was smaller in SHR than in WKY, and was also endothelium-dependent. Moreover, release of endothelial NO in response to acute leptin was higher in WKY compared to SHR, but completely abolished in the absence of endothelium. In conclusion, the reduced anticontractile effect of PVAT in SHR might be attributed to a reduced PVAT-derived leptin and to an abrogated effect of leptin on endothelial NO release probably due to an impaired activation of endothelial NO synthase.

Keywords: perivascular adipose tissue, hypertension, angiotensin II, leptin, nitric oxide

\section{INTRODUCTION}

Perivascular adipose tissue (PVAT) is now considered a highly active endocrine organ that releases a variety of adipokines, inflammatory cytokines, and other factors which influence vascular tone in a paracrine way (Gollasch and Dubrovska, 2004; Gao, 2007). PVAT releases a number of vasodilatory factors, such as adipocyte-derived relaxing factor (ADRF; Löhn et al., 2002; Dubrovska et al., 2004; Verlohren et al., 2004; Gálvez et al., 2006), leptin (Payne et al., 2010; Dashwood et al., 2011), adiponectin (Fesüs et al., 2007), angiotensin 1-7 (Ang 1-7; Lee et al., 2009), hydrogen peroxide (Gao et al., 2007), and nitric oxide (NO; GilOrtega et al., 2010). Moreover, PVAT also releases vasoconstrictor factors such as angiotensin II (Ang II; Gálvez-Prieto et al., 2008) and superoxide anion (Gao et al., 2006). Under physiological conditions, PVAT elicits a net anticontractile beneficial effect on vascular function that is essential for the maintenance of vascular resistance. In presence of PVAT, arteries and veins from different species, including human, exhibit lower contractions to a variety of vasoconstrictors than arteries cleaned of PVAT.

Perivascular adipose tissue undergoes structural and functional changes in pathophysiological conditions. During early diet-induced obesity (DIO) an adaptative NO overproduction occurs in PVAT, probably aimed at protecting vascular function
(Gil-Ortega et al., 2010). However, in established obesity, PVAT looses its anticontractile properties (Gao et al., 2005) by an increase of oxidative stress that leads to endothelial dysfunction (GilOrtega et al., 2009). In spontaneously hypertensive rats (SHR), a lean model of hypertension, mesenteric adipose pads are lighter compared to normotensive Wistar-Kyoto rats (WKY; Gálvez et al., 2006). Accordingly, plasma and mesenteric leptin content are also reduced in this strain. The lower amount of adipose tissue (AT) facilitates contraction in mesenteric arteries, likely attributable to a diminished paracrine regulation of perivascular fat on mesenteric arterial tone via Kv channels (Gálvez et al., 2006). Moreover, periaortic AT from SHR also shows a reduced anticontractile effect, probably related to the increase in the number of brown adipocytes and to a reduction in the production of Ang 1-7 (Lu et al., 2011).

Leptin is a lipostatic hormone synthesized mainly by white AT (Zhang et al., 1994) and to a minor extent by brown adipocytes (Cannon and Nedergaard, 2004). Leptin monitors the status of energy reserves being more secreted the larger the adipocytes are. Consequently, plasma leptin concentration correlates with the amount of AT (Schwartz et al., 1996; Somoza et al., 2007). Leptin also participates in the regulation of vascular tone, although mechanisms are still unclear and contradictory (for review, see Knudson et al., 2008). Vascular effects of leptin seem to be the 
net result of two different actions: (i) indirect vasoconstriction through stimulation of sympathetic activity at hypothalamic level (Elias et al., 1998; Hall et al., 2000) and (ii) direct vasodilation, that depends on an intact and functional endothelium, through mechanisms that vary between different vascular beds and species. In vivo experiments in rats have revealed that leptin infusion reduces arterial pressure by increasing NO (Frühbeck, 1999). In isolated aorta, vasodilation involves NO release (Sahin et al., 2009) through a mechanism linked to the activation of endothelial NO synthase (eNOS) via Akt-dependent phosphorylation of eNOS at $\operatorname{Ser}^{1177}$ (Lembo et al., 2000; Vecchione et al., 2002). In rat mesenteric arteries, leptin induces the release of endotheliumderived hyperpolarizing factor (Lembo et al., 2000). Moreover, an endothelium-independent anticontractile effect of leptin on Ang II-induced contractions has been described. In humans, leptin induces vasodilation in saphenous vein and internal mammary artery through an endothelium-independent mechanism (Momin et al., 2006). Abrogated vasodilatory and antiproliferative effects of leptin have been reported in blood vessels from SHR (Fortuño et al., 2002; Rodriguez et al., 2007; Rodríguez et al., 2010), contributing to an increase in vascular contractions.

The hypothesis of the current study is that the decrease of anticontractile effect of PVAT observed in SHR deals with a downregulation of leptin production within this tissue. Our aim was to characterize in both SHR and WKY aorta (i) leptin expression and protein in PVAT, (ii) the vasodilatory effect and NO production elicited by leptin, and (iii) the effect of leptin and PVAT on contractile responses.

\section{MATERIALS AND METHODS \\ ANIMALS}

Experiments were conducted in 3-month-old male WKY and SHR (250-300 g; Charles River, Barcelona, Spain) maintained under controlled light ( $12 \mathrm{~h}$ light cycles from 8.00 to 20.00 hours) and temperature $\left(22-24^{\circ} \mathrm{C}\right)$ conditions. Rats were fed a normal rat chow (A.04, Panlab, Barcelona, Spain) and had free access to tap water. Systolic blood pressure was monitored under sodium pentobarbital anesthesia ( $50 \mathrm{mg} / \mathrm{kg}$; i.p.) in a group of SHR as previously described (Gálvez et al., 2006). The Institutional Animal Care and Use Committee approved all experimental procedures according to the guidelines for ethical care of experimental animals of the European Community.

For sampling and functional measures animals $(n=16$ per strain) were killed by decapitation. We avoided $24 \mathrm{~h}$ fasting because fasting stimulates lipid mobilization and lipolysis and decreases plasma leptin concentration (Cano et al., 2003). Therefore, we performed plasma extraction in the morning, thus plasma values corresponding to postprandial concentrations. Blood was collected in EDTA-coated tubes, and plasma preserved after centrifugation at $-20^{\circ} \mathrm{C}$ until biochemical assays. The aorta was quickly dissected and preserved in oxygenated Krebs solution until used for functional or confocal microscopy studies. Periaortic AT was frozen at $-80^{\circ} \mathrm{C}$ for determination of leptin expression and protein levels.

\section{RNA ISOLATION, REVERSE TRANSCRIPTION, AND QUANTITATIVE REAL-TIME PCR FOR LEPTIN EXPRESSION}

Total RNA of AT was isolated using RNeasy ${ }^{\circledR}$ Lipid Tissue Mini Kit (Qiagen, Hilden, Germany) according to the manufactures protocol. An on-column DNase digestion step was included in the protocol with RNase-Free DNase Set (Qiagen, Hilden, Germany) to minimize genomic contamination. Concentration and purity of isolated RNA was determined by measuring the extinction at 260 and $280 \mathrm{~nm}$. One microgram total RNA was reverse transcribed in $40 \mu \mathrm{l}$ final volume using First Strand cDNA Synthesis Kit (Fermentas GmbH, St. Leon-Rot, Germany) according to the manufacturer's instructions. Transcribed cDNA was stored at $-20^{\circ} \mathrm{C}$ until further use.

To quantify expression levels of leptin we employed the realtime quantitative RT (“TaqMan”) PCR. Briefly, the ABI PRISM ${ }^{\circledR}$ 7000 SDS instrument in conjunction with the ABI TaqMan Universal Master Mix (Applied Biosystems, Darmstadt, Germany) was used to perform the assays with a final concentration of $300 \mathrm{nM}$ for the primers and $100 \mathrm{nM}$ for the probes. Fluorogenic probes and primers were synthesized by TIB Molbiol (Berlin, Germany). Sense, antisense primer and probe sequences for leptin were the following, respectively: $5^{\prime}$-AACCCTCATCAAGA CCATTGTCA-3', 5'-GGTCCATCTTGGACAAACTCAGA-3', 5' CTTCATTCCCGGGCTTCACCCC- $3^{\prime}$. To avoid signals of genomic origin intron spanning primers were used and primers were checked for genomic signal before use. Specificity of the product was confirmed by sequencing. Relative quantification was done using the standard curve method. Every sample was measured in triplicate. To normalize our expression data we used $18 \mathrm{~S}$ as a housekeeping gene.

\section{WESTERN BLOT OF LEPTIN Ob-R RECEPTORS}

$\mathrm{Ob}-\mathrm{Rb}$ proteins were measured in aorta from SHR and WKY. Briefly, tissues were homogenized in ice-cold buffer containing $0.42 \mathrm{M} \mathrm{NaCl}, 20 \mathrm{mM}$ HEPES ( $\mathrm{pH} 7.9$ ), $1 \mathrm{mM} \mathrm{Na} \mathrm{P}_{2} \mathrm{O}_{7}, 1 \mathrm{mM}$ EDTA, $1 \mathrm{mM}$ EGTA, $1 \mathrm{mM}$ dithiothreitol, $20 \%$ glycerol, $1 \mu \mathrm{g} / \mathrm{ml}$ aprotinin, $1 \mu \mathrm{g} / \mathrm{ml}$ leupeptin, $20 \mathrm{mM}$ sodium fluoride, $1 \mathrm{mM}$ trisodium orthovanadate, and $2 \mathrm{mM}$ phenylmethylsulfonyl fluoride. Tubes containing homogenates were frozen at $-80^{\circ} \mathrm{C}$ and thawed at $37^{\circ} \mathrm{C}$ three consecutive times, then centrifuged for $10 \mathrm{~min}$ at $4^{\circ} \mathrm{C}$. Equivalent amounts of proteins $(50 \mu \mathrm{g})$ present in the supernatant were loaded in Laemmli buffer $(50 \mathrm{mM}$ Tris $\mathrm{pH}=6.8,10 \%$ SDS, $10 \%$ glycerol, 5\% mercaptoethanol, and $2 \mathrm{mg} / \mathrm{ml}$ blue bromophenol) and size-separated in 15\% SDSpolyacrylamide gel electrophoresis. Proteins were transferred to PVDF membranes (Amersham Pharmacia, Spain) using a transblot apparatus (Bio-Rad, Spain). For immunoblotting, membranes were blocked with $5 \%$ non-fat dried milk in Tween-PBS (TPBS) for $1 \mathrm{~h}$. Primary antibodies against pSTAT3 $\left(\mathrm{Tyr}^{705}\right.$; Cell Signaling Technology, USA; 1/100 final dilution), STAT3 (Santa Cruz Biotechnology, USA; 1/1000 final dilution), or leptin receptor (Affinity Bioreagents, USA, 1/2000 final dilution) were applied overnight at $4^{\circ} \mathrm{C}$. After washing, appropriate secondary antibodies (anti-goat IgG-peroxidase conjugated) were applied for $1 \mathrm{~h}$ at a dilution of 1/10000. Blots were washed, incubated in commercial enhanced chemiluminescence reagents (ECL, Amersham Bioscience, UK) and exposed to autoradiographic film. To prove equal loadings of samples, blots were re-incubated with $\beta$-actin antibody (Affinity Bioreagents, USA). Films were scanned using a GS-800 Calibrated Densitometer (Bio-Rad, Spain) and blots were quantified using Quantity One software (Bio-Rad, Spain). Values 
for $\mathrm{Ob}-\mathrm{Rb}$ were normalized with $\beta$-actin to account for variations in gel loading.

\section{LEPTIN ASSAY}

Leptin concentration in plasma and periaortic AT was analyzed by using a specific enzyme immunoassay (ELISA) kit for rat leptin (Assay Designs Inc., USA) as previously described (Gálvez et al., 2006). Intra-assay and inter-assay variations were 11.6 and $11 \%$, respectively.

\section{FUNCTIONAL STUDIES}

The aorta was carefully isolated, placed in oxygenated physiological salt solution (PSS), and cleaned of blood and perivascular fat. PSS had the following composition: $115 \mathrm{mM} \mathrm{NaCl}$, $4.6 \mathrm{mM} \mathrm{KCl}, 2.5 \mathrm{mM} \mathrm{CaCl}_{2}, 25 \mathrm{mM} \mathrm{NaHCO}_{3}, 1.2 \mathrm{mM} \mathrm{KH}_{2} \mathrm{PO}_{4}$, $1.2 \mathrm{mM} \mathrm{MgSO}_{4}, 0.01 \mathrm{mM}$ EDTA, and $5.5 \mathrm{mM}$ glucose. All experiments were performed in presence of dexamethasone $(0.8 \mu \mathrm{M})$ and indomethacin $(5 \mu \mathrm{M})$ to avoid iNOS induction and prostaglandin-mediated effects, respectively. Preincubation with these drugs did not modify the anticontractile effect of PVAT. After an equilibration period of $90 \mathrm{~min}$ and before starting the experiment, aortic rings were contracted with $\mathrm{KCl} 75 \mathrm{mM}$ to assess their contractility. Subsequently, segments were contracted with phenylephrine $\left(10^{-7} \mathrm{M}\right)$ and acetylcholine (Ach, $10^{-9}$ to $10^{-4} \mathrm{M}$ ) was added to functionally confirm the presence of the endothelium. Rat leptin (Sigma, USA) was tested between $10^{-10}$ and $10^{-8} \mathrm{M}$ in vessels preconstricted with $\mathrm{U} 46619\left(10^{-7} \mathrm{M}\right.$; Sigma, USA). In order to confirm that leptin vasodilation is endothelium-dependent, a set of experiments was carried out in endothelium-denuded segments.

\section{DETERMINATION BY CONFOCAL MICROSCOPY OF NO AVAILABILITY AFTER LEPTIN STIMULATION}

Nitric oxide availability was determined by the fluorescent NO indicator 4,5-diaminofluorescein diacetate (DAF-2, Sigma) as previously described (Somoza et al., 2005; Arribas et al., 2007). Intact and endothelium-denuded aortas were cut in $3 \mathrm{~mm}$ segments and stabilized in PSS containing $0.8 \mu \mathrm{M}$ dexamethasone (to avoid iNOS induction) and $15 \mathrm{U} / \mathrm{ml} \mathrm{SOD} \mathrm{(to} \mathrm{avoid} \mathrm{NO} \mathrm{inactivation} \mathrm{by}$ superoxide anions) for $30 \mathrm{~min}$ at $37^{\circ} \mathrm{C}$. Thereafter, the segments were stained with $10^{-5} \mathrm{M}$ DAF-2 dissolved in PSS and incubated in the darkness at room temperature in a shaking bath for $30 \mathrm{~min}$ in the presence or absence of leptin $(10 \mathrm{ng} / \mathrm{ml})$. Some segments were incubated with Ach $\left(10^{-6} \mathrm{M}\right.$, positive controls) or $10^{-4} \mathrm{M}$ L-NAME ( $\mathrm{N}^{\omega}$-nitro-L-arginine methyl ester; negative controls) throughout the experimental period. Following the $30 \mathrm{~min}$ DAF-2 incubation period, the arterial segments were cut in $50 \mu \mathrm{m}$ thick rings, washed in PSS and mounted on slides for visualization with a Leica TCS SP2 confocal system (Leica Microsystems, Germany) fitted with argon and helio-neon laser sources and coupled to a Leica DMIRE 2 microscope, using the $488 / 515 \mathrm{~nm}$ line of the microscope. Stacks of 15 serial optical sections ( $1 \mu \mathrm{m}$ thick) were captured from each ring with a $20 \times$ objective, $2 \times$ zoom and a maximal projection was then obtained. All images from control and stimulated rings were captured under identical conditions of laser intensity, brightness, and contrast. From these images, reconstructions were obtained and quantification of fluorescence intensity into nuclei was determined by using Image-J (N.I.H. USA).

\section{STATISTICAL ANALYSIS}

All values are given as mean \pm SEM. Student's $t$ tests or ANOVA were used as appropriate. A value of $p<0.05$ was considered statistically significant.

\section{RESULTS}

\section{CHARACTERIZATION OF ANIMALS}

Spontaneously hypertensive rats exhibited significantly elevated systolic and diastolic blood pressures than WKY $(179 \pm 8$ and $136 \pm 6 \mathrm{~mm} \mathrm{Hg}$ vs. $131 \pm 4$ and $95 \pm 6 \mathrm{~mm} \mathrm{Hg}$, respectively; $p<0.05)$. Moreover, there was no significant difference in body weight between WKY and SHR ( $400 \pm 8$ vs. $404 \pm 10 \mathrm{~g})$.

As summarized in Table 1, lumbar and mesenteric pads were lighter in SHR than in WKY $(p<0.05)$. Periaortic AT amount was, however, similar between both strains. Plasma leptin concentration in WKY $(11.5 \pm 2.2 \mathrm{ng} / \mathrm{ml})$ and SHR $(7.6 \pm 1.0 \mathrm{ng} / \mathrm{ml}$; $p<0.05)$ exhibited a positive correlation with the total amount of AT ( $r=0.84 ; p<0.05)$. Other metabolic features of WKY and SHR have been analyzed in a previous study (Gálvez et al., 2006).

\section{THE ANTICONTRACTILE EFFECT OF PVAT IS REDUCED IN SHR}

Concentration-response curves to Ang II were compared in presence and in absence of PVAT. To exclude participation of periaortic-derived ADRF, which acts through $\mathrm{K}_{\mathrm{ATP}}$ channels (Löhn et al., 2002), these experiments were performed in presence of glibenclamide $(5 \mu \mathrm{M})$ which significantly reduced the anticontractile effect of PVAT in WKY (results not shown). However a significant anticontractile effect of PVAT was still maintained as shown in Figures 1A,B and Table 2. The presence of PVAT significantly reduced contractions to Ang II only in aortic rings from WKY. No changes were observed in $\mathrm{pD}_{2}$ values between groups (Table 2). In SHR, contractions to Ang II were more potent and effective compared to WKY independently of PVAT (Table 2). No differences were observed between groups in $75 \mathrm{mM} \mathrm{KCl}$-induced contractions, as previously described (Gálvez et al., 2006).

In the absence of endothelium, contractions to Ang II were significantly higher in aortic segments of both WKY and SHR cleaned of PVAT (Figures 1C,D; Table 2). The anticontractile effect of PVAT was lost in endothelium-denuded rings from WKY independently of the presence of PVAT (Table 2). No effect of PVAT was observed in endothelium-independent relaxations to sodium nitroprusside (SNP, $10^{-12}$ to $10^{-5} \mathrm{M}$; results not shown).

\section{LEPTIN mRNA AND PROTEIN EXPRESSION ARE REDUCED IN PERIAORTIC ADIPOSE TISSUE FROM SHR}

To determine if alterations in leptin production by PVAT might influence aortic function we determined leptin levels in PVAT.

Table 1 | Adipose tissue weights in 3-month-old male WKY and SHR.

\begin{tabular}{lll}
\hline & WKY & SHR \\
\hline Lumbar adipose tissue (g) & $2.1 \pm 0.1$ & $1.8 \pm 0.1(p<0.05)$ \\
Mesenteric adipose tissue (g) & $3.5 \pm 0.1$ & $3.1 \pm 0.1(p<0.05)$ \\
Periaortic adipose tissue (mg) & $207 \pm 11$ & $183 \pm 15$
\end{tabular}

Data are expressed as mean \pm SEM. Number of data $n=16-18$ animals per strain. 

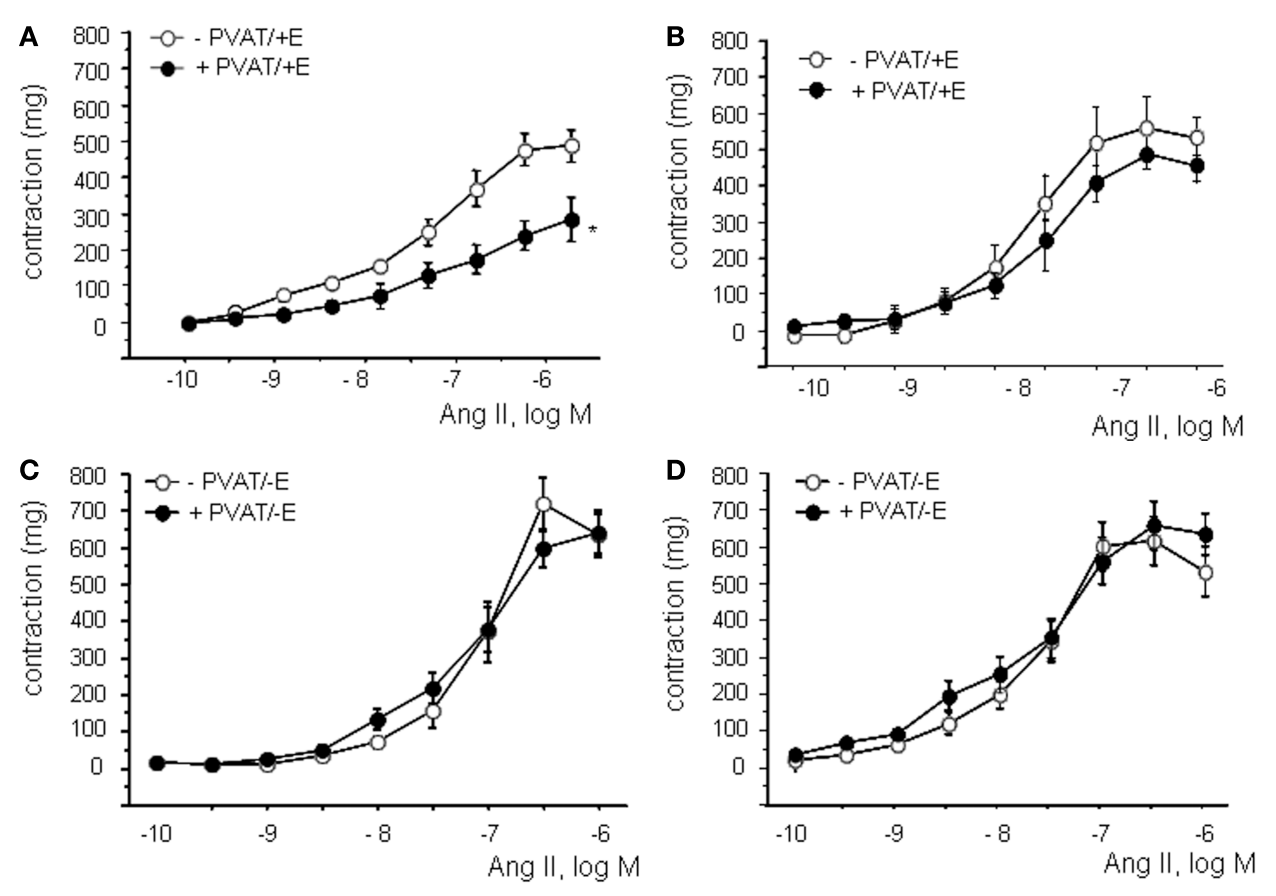

FIGURE 1 | Effect of PVAT on angiotensin II (Ang II)-induced contractions in aortic rings from WKY (A) and SHR (B). Effect of endothelial removal on angiotensin II (Ang II)-induced contractions in aortic rings from WKY (C) and SHR (D) in presence and absence of PVAT. Data are expressed in milligram and shown as mean \pm SEM of 10 animals per strain.
Table 2 | Effect of PVAT or leptin on Emax and pD2 values of concentration-response curves to Ang II.

\begin{tabular}{llllll}
\hline & \multicolumn{2}{c}{ WKY } & & \multicolumn{2}{c}{ SHR } \\
\cline { 2 - 3 } \cline { 5 - 6 } & Emax (mg) & pD2 & & Emax (mg) & pD2 \\
\hline -PVAT/+E & $497 \pm 21$ & $7.3 \pm 0.2$ & & $598 \pm 49^{\#}$ & $8.2 \pm 0.2^{\#}$ \\
+PVAT/+E & $289 \pm 15^{*}$ & $7.4 \pm 0.2$ & & $502 \pm 58^{\#}$ & $8.3 \pm 0.2^{\#}$ \\
-PVAT/-E & $734 \pm 69^{\S}$ & $7.1 \pm 0.2$ & $688 \pm 39^{\S}$ & $7.9 \pm 0.2^{\#}$ \\
-PVAT/-E & $650 \pm 53^{\S}$ & $7.3 \pm 0.2$ & $642 \pm 39^{\S}$ & $7.8 \pm 0.2^{\#}$ \\
-Leptin/+E & $411 \pm 32$ & $7.2 \pm 0.2$ & $640 \pm 100^{\#}$ & $7.6 \pm 0.1^{\#}$ \\
+Leptin/+E & $231 \pm 35^{*}$ & $7.2 \pm 0.2$ & & $582 \pm 51^{\#}$ & $7.6 \pm 0.2^{\#}$ \\
- Leptin/-E & $665 \pm 63^{\S}$ & $7.1 \pm 0.2$ & & $698 \pm 52$ & $7.6 \pm 0.2^{\#}$ \\
+Leptin/-E & $648 \pm 51^{\S}$ & $7.1 \pm 0.1$ & $680 \pm 32^{\S}$ & $7.7 \pm 0.2^{\#}$ \\
\hline
\end{tabular}

* Significant effect of PVAT or leptin $(p<0.05)$ : comparison between -PVAT and $+P V A T$ rings or -leptin and +leptin rings.

"Significant effect of strain $(p<0.05)$ : comparison between WKY and SHR rings. ${ }^{s}$ Significant effect of endothelium $(p<0.05)$ : comparison between $+E$ and $-E$ rings.

Figure 2 summarizes the results obtained in the analysis of leptin mRNA and protein levels in periaortic AT. Periaortic leptin levels were significantly lower in SHR $(p<0.05)$ both at mRNA (Figure 2A) as well as at protein level (Figure 2B).

\section{LEPTIN REDUCES Ang II-INDUCED CONTRACTIONS IN WKY BUT NOT IN SHR}

After preincubation with leptin $(10 \mathrm{nM})$, concentration-response curves to Ang II $\left(10^{-10}\right.$ to $\left.10^{-6} \mathrm{M}\right)$ were performed in aortic

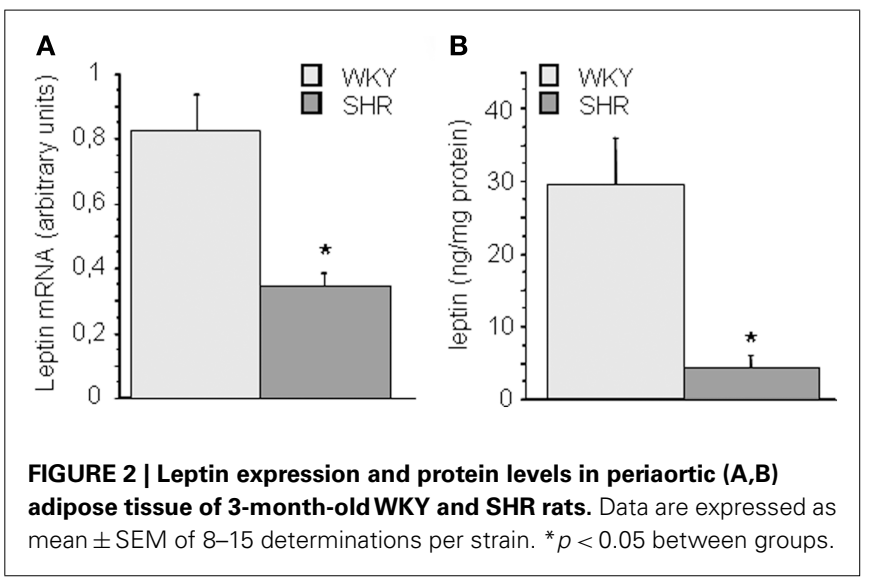

rings of both strains (Figure 3; Table 2). Leptin induced a significant reduction of Ang II-induced contractions in rings from WKY, whereas the effect of leptin was almost absent in rings from SHR (Figures 3A,B). The anticontractile effect of leptin was abolished in endothelium-denuded rings (Figures 3C,D).

\section{VASODILATORY EFFECT OF LEPTIN IS REDUCED IN AORTA OF SHR}

Leptin $\left(10^{-10}\right.$ to $\left.10^{-8} \mathrm{M}\right)$ induced a concentration-dependent vasodilation in aortic rings from WKY, which was almost abolished in arteries from SHR (Figure 4A). Vasodilatory effect of leptin was weak reaching a maximal response of 30 and of $5 \%$ of previous contraction in WKY and SHR, respectively. Endothelium removal and incubation with $0.1 \mathrm{mM}$ L-NAME completely abolished relaxation to leptin (results nor shown), suggesting the 

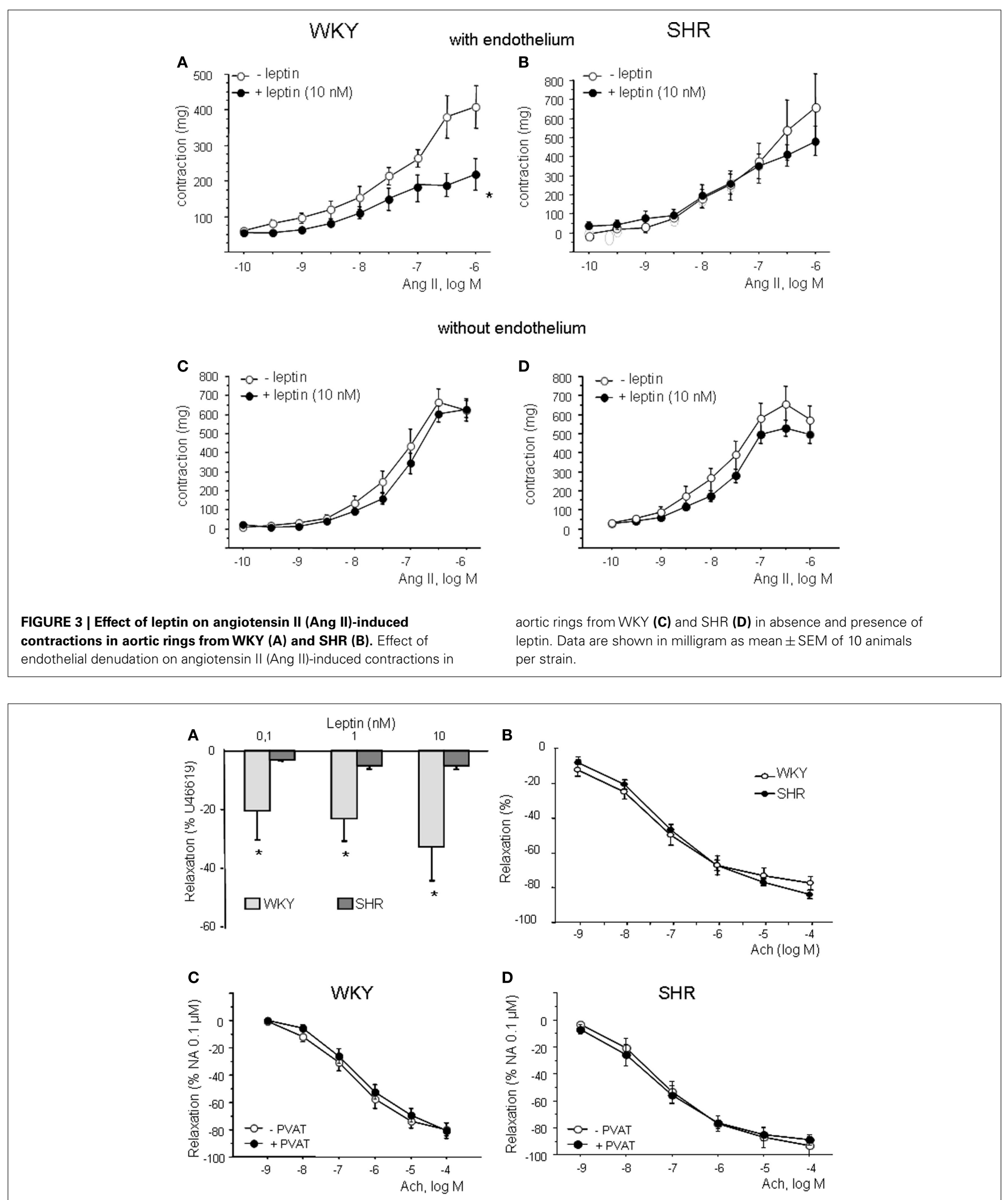

FIGURE 4 | Concentration-response curve to leptin $\left(10^{-10}\right.$ to $\left.10^{-8} \mathrm{M}\right)$ (A) and acetylcholine $\left(10^{-9}\right.$ to $\left.10^{-4} \mathrm{M}\right)(B)$ in aortic rings from WKY and SHR. Concentration-response curve to Ach in aortic rings from WKY (C) and

SHR (D) in presence and absence of PVAT. Relaxation is expressed as percentage of a previous contraction to $U 46619\left(10^{-7} \mathrm{M}\right)$. Data are shown as mean \pm SEM of 10 animals per strain. 


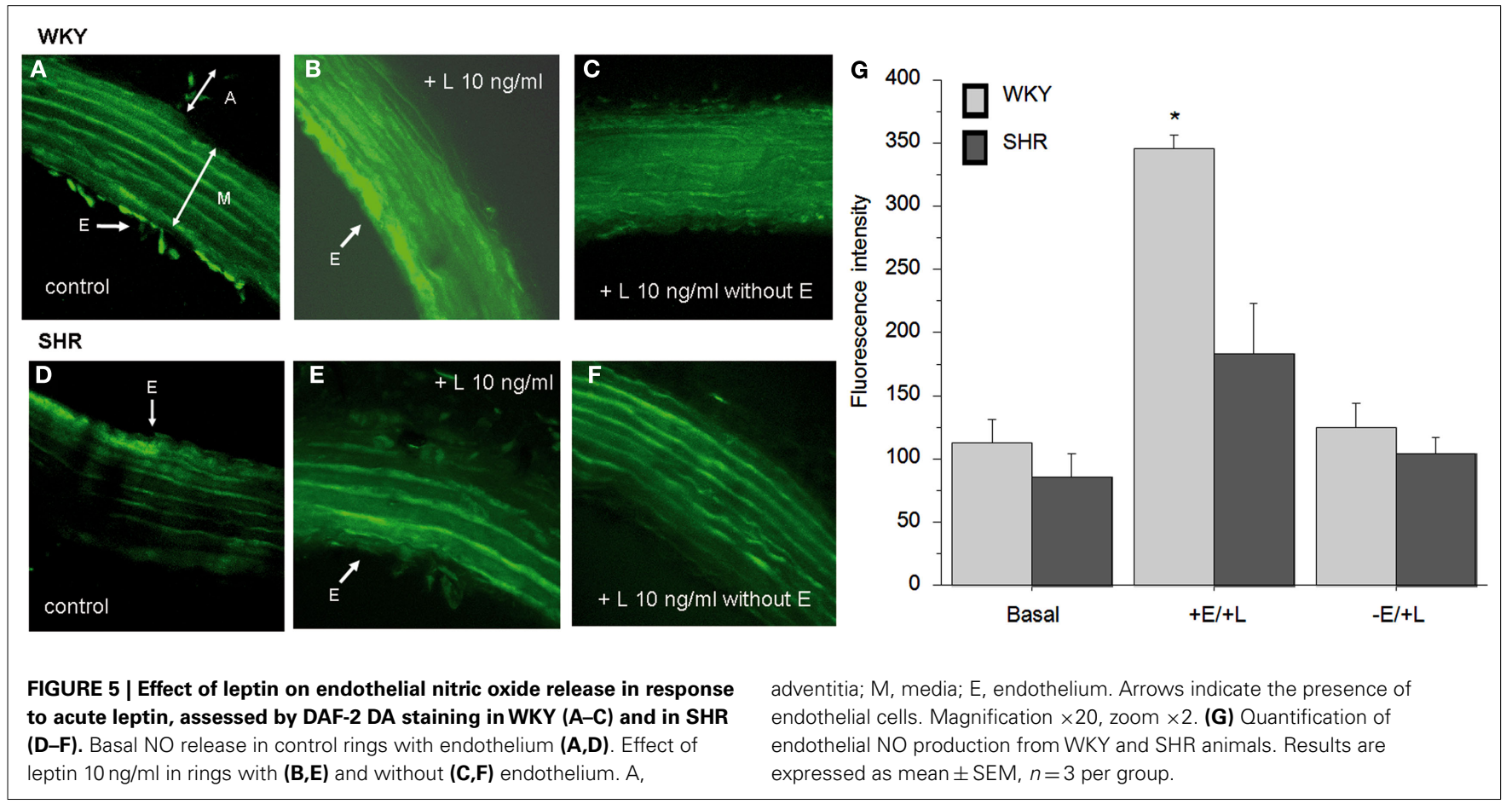

involvement of $\mathrm{NO}$ in this response, as previously observed in rat aorta (Kimura et al., 2000; Lembo et al., 2000).

The reduced effect of leptin in SHR cannot be attributed to endothelial dysfunction in this strain since Ach induced a similar concentration-dependent relaxation $\left(10^{-9}\right.$ to $\left.10^{-4} \mathrm{M}\right)$ in aorta from WKY and SHR (Figure 4B). No influence of PVAT could be observed in Ach-induced relaxation (Figures 1D and 4C,D), as previously observed in mesenteric arteries (Gálvez et al., 2006). Moreover, there were no differences in $\mathrm{Ob}-\mathrm{Rb}$ receptor expression between strains (WKY: $1.3 \pm 0.1$ arbitrary units vs. SHR: $1.2 \pm 0.2$ arbitrary units; n.s.)

\section{LEPTIN-INDUCED RELEASE OF NO IS LOWER IN SHR}

To support the functional studies, we investigated leptin-induced NO production in aortic segments by using the fluorescent NO indicator DAF2-DA. In order to exclude the interaction with superoxide anions, all segments were incubated simultaneously with SOD $(15 \mathrm{U} / \mathrm{ml})$. Green fluorescence was negligible in the artery ring in the presence of L-NAME (results not shown). In aortic rings from WKY, leptin $(10 \mathrm{nM})$ induced a robust increase in NO production (Figure $5 \mathbf{B}$ ), when compared to control rings (Figures 5A,G). The effect of leptin was significantly reduced in aortic rings from SHR (Figures 5D,E,G). NO production was dependent on the presence of endothelium, since fluorescence was completely abolished in endothelium-denuded rings from both strains (Figures 5C,F).

\section{DISCUSSION}

This study shows that the anticontractile effect of PVAT is absent in SHR. Main findings of this study are that (i) leptin production is reduced in periaortic AT from SHR and (ii) that vasodilatory and anticontractile effects of leptin are abolished in SHR aorta. The diminished vascular effects are due to an impairment of leptin-mediated NO release from the endothelium. These findings suggest that the reduction of leptin production by PVAT may contribute to increased vascular contractions observed in SHR.

The endothelium-dependent anticontractile effect of PVAT detected in aortic rings from WKY incubated with Ang II, suggests a paracrine effect of a PVAT-derived factor. Although leptin antagonists (pegylated leptin inhibitor) have been successfully used in pig coronary arteries (Payne et al., 2010), they were unable to block leptin-induced responses in our model, probably due to species differences (data not shown). As these drugs are not useful tools to antagonize the anticontractile effect of PVAT, we chose an indirect approach and we characterized the effect of exogenous leptin on PVAT-cleaned aortic rings. Leptin induced a weak concentration-dependent relaxation, which was endothelium-dependent and linked to NO production, as previously observed in other studies (Kimura et al., 2000; Lembo et al., 2000). Moreover, and as observed with PVAT, leptin significantly reduced Ang II-induced contractions. The anticontractile effect of leptin was lost in endothelium-denuded rings. Thus, the effect of leptin fully mimicked the anticontractile effect of PVAT. However, this coincidence does not allow concluding that leptin accounts for the anticontractile effect of PVAT and studies carried out with new specific leptin receptor antagonists would be necessary to address this question. Otherwise, the participation of other adipose relaxant factors (Fesüs et al., 2007; Gao et al., 2007; Lee et al., 2009; Gil-Ortega et al., 2010; Gollasch, 2012) cannot be excluded, with the exception of ADRF, since all experiments were performed in presence of glibenclamide $(5 \mu \mathrm{M})$, an inhibitor of $\mathrm{K}_{\mathrm{ATP}}$ channels implicated in ADRF-induced aortic vasodilatation (Löhn et al., 2002; Zeng et al., 2009). In summary, the hypothesis that leptin might play a pivotal role on the anticontractile effect of PVAT cannot be demonstrated conclusively with these functional data. 
A main finding of this study is that leptin mRNA and protein expression are lower in PVAT from SHR compared to WKY. This might be related to the increased sympathetic outflow in this strain (Frohlich and Pfeffer, 1975; Cabassi et al., 2002). Leptin expression in brown adipocytes depends on AT activity. Conditions associated with activation of brown AT, such as sympathetic stimulation or cold, decrease leptin gene expression often down to undetectable levels (Cannon and Nedergaard, 2004). Moreover, adrenergic stimulation via $\beta_{3}$-adrenoceptors (Buyse et al., 2001) is also associated with lower lipid content in the cells, i.e., smaller brown adipocytes. Norepinephrine also promotes proliferation of brown preadipocytes and differentiation in mature brown adipocytes (Cannon and Nedergaard, 2004). Interestingly, Gao and colleagues have recently suggested that the number of brown adipocytes in aortic PVAT of SHR is higher than in WKY, without differences in the amount of PVAT (Lu et al., 2011). We do not find differences either in the amount of periaortic AT between strains.

The poor vasodilatory/anticontractile effect of leptin detected in SHR aorta might be due to a reduced NO release from the endothelium, as shown by DAF2-DA staining. In accordance with our results, an abrogated effect of leptin has been reported in different organs from hypertensive animal models (Fortuño et al., 2002; Wold et al., 2002; Villarreal et al., 2006; Rodriguez et al., 2007). This effect cannot be attributed to endothelial dysfunction, since relaxation to Ach was similar between strains. This latter observation is in agreement with previous reports showing that young SHR (12 weeks of age) and some SHR strains are particularly resistant to end organ damage, maintaining normal endothelial function despite the hypertension (Gschwend et al., 2002). Moreover, it has to be noted that all experiments were performed in the presence of indomethacin to exclude participation of vasoconstrictor prostanoids, which is the main mechanism of endothelial dysfunction in aorta from SHR (Lüscher and Vanhoutte, 1986).

The anticontractile effect of PVAT on Ang II-induced contractions was also abolished in SHR. A similar effect has been described for phenylephrine-induced contractions correlating with a lower ADRF release (Zeng et al., 2009) or Ang 1-7 release (Lu et al., 2011). Consequently, we propose that the different anticontractile

\section{REFERENCES}

Arribas, S. M., Daly, C. J., Gonzalez, M. C., and McGrath, J. C. (2007). Imaging the vascular wall using confocal microscopy. J. Physiol. 584, 5-9.

Buyse, M., Viengchareun, S., Bado, A., and Lombes, M. (2001). Insulin and glucocorticoids differentially regulate leptin transcription and secretion in brown adipocytes. FASEB $J$. $15,1357-1366$.

Cabassi, A., Vinci, S., Cantoni, A. M., Quartieri, F., Moschini, L., Cavazzini, S., Cavatorta, A., and Borghetti, A. (2002). Sympathetic activation in adipose tissue and skeletal muscle of hypertensive rats. Hypertension 36, 656-661.

Cannon, B., and Nedergaard, J. (2004). Brown adipose tissue: function and physiological significance. Physiol. Rev. 84, 277-359.

Cano, V., Ezquerra, L., Ramos, M. P., and Ruiz-Gayo, M. (2003). Regulation of leptin distribution between plasma and cerebrospinal fluid by cholecystokinin receptors. Br. J. Pharmacol. $140,647-652$.

Da Silva, B. A., Bjorbaek, C. S., and Flier, J. S. (1998). Functional properties of leptin receptor isoforms containing the Gln-Pro extracellular

effect of PVAT between strains might be attributed to two aspects: (i) PVAT-derived leptin is significantly lower in SHR and (ii) leptin has almost no effect on endothelial NO release in SHR, probably due to an impaired activation of eNOS.

A question of additional interest concerns the partial contribution of circulating and PVAT-derived leptin to the regulation of vascular tone, which would be linked to the role of leptin either as an endocrine and/or as a paracrine/autocrine mediator involved in regulating arterial function. We might reason that differences in plasma leptin concentration between strains, although statistically significant, would not account for relevant differences in leptin receptor occupancy. In fact, the $\mathrm{K}_{\mathrm{D}}$ of leptin for leptin receptors has been estimated between 0.4 and $0.7 \mathrm{nmol} / \mathrm{l}$ (Da Silva et al., 1998). In our experimental model plasma leptin ranges between $7.6 \mathrm{ng} / \mathrm{ml}$ (approximately $0.47 \mathrm{nM}$ ) and $11.5 \mathrm{ng} / \mathrm{ml}$ (approximately $0.72 \mathrm{nM}$ ) in WKY and SHR, respectively. Thus, it can be estimated that leptin receptor occupancy is close to $50 \%$ in both strains. Nevertheless, a role for circulating leptin cannot be excluded, since at this receptor occupancy the vasodilatory effect of leptin between 0.1 and $1 \mathrm{nM}$ is significantly reduced both in aorta and mesenteric arteries from SHR (Gálvez et al., 2006).

In conclusion, this study shows that PVAT-derived leptin might contribute, together with other relaxant factors, to the net anticontractile effect of PVAT. This effect is abolished in aorta from SHR probably due to both a reduced leptin mRNA and protein expression in PVAT and to an impairment of leptin-mediated NO release from the endothelium. We suggest that PVAT is a tissue with high plasticity, responding to different physiological and physiopathological situations through phenotypic changes in either tissue amount, morphology, or in the balance of vasoactive factors.

\section{ACKNOWLEDGMENTS}

This work was supported by grants from Ministerio de Educación y Ciencia (SAF 2009-09714, SAF2008-02703), Grupos UCM GR-921641, Fundación Universitaria San Pablo-CEU, Fundación Mutua Madrileña, and SESCAMET. Ana I. de las Heras and Marta Gil-Ortega are fellows from MEC. Concha F. García-Prieto is a fellow from CEU-Universidad San Pablo.

domain mutation of the fatty rat. Endocrinology 139, 3681-3690.

Dashwood, M. R., Dooley, A., Shi-Wen, X., Abraham, D. J., Dreifaldt, M., and Souza, D. S. (2011). Perivascular fat-derived leptin: a potential role in improved vein graft performance in coronary artery bypass surgery. Interact. Cardiovasc. Thorac. Surg. 12, 170-173.

Dubrovska, G., Verlohren, S., Luft, F. C., and Gollasch, M. (2004). Mechanisms of ADRF release from rat aortic adventitial adipose tissue. Am. J. Physiol. 286, 1107-1113.

Elias, C. F., Lee, C., Kelly, J., Aschkenasi, C., Ahima, R. S., Couceyro, P.
R., Kuhar, M. J., Saper, C. B., and Elmquist, J. K. (1998). Leptin activates hypothalamic CART neurons projecting to the spinal cord. Neuron 21, 1375-1385.

Fesüs, G., Dubrovska, G., Gorzelniak, K., Kluge, R., Huang, Y., Luft, F. C., and Gollasch, M. (2007). Adiponectin is a novel humoral vasodilator. Cardiovasc. Res. 75, 719-727.

Fortuño, A., Rodriguez, A., GomezAmbrosi, J., Muñiz, P., Salvador, J. Diez, J., and Frühbeck, G. (2002). Leptin inhibits angiotensin II-induced intracellular calcium increase and vasoconstriction in rat aorta. Endocrinology 143, 3555-3560. 
Frohlich, E. D., and Pfeffer, M. A. (1975). Adrenergic mechanisms in human hypertension and in spontaneously hypertensive rats. Clin. Sci. Mol. Med. Suppl. 2, 225s-238s.

Frühbeck, G. (1999). Pivotal role of nitric oxide in the control of blood pressure after leptin administration. Diabetes 48, 903-908.

Gálvez, B., de Castro, J., Herold, D., Dubrovska, G., Arribas, S., González, M. C., Aranguez, I., Luft, F. C., Ramos, M. P., Gollasch, M., and Fernández-Alfonso, M. S. (2006). Perivascular adipose tissue and mesenteric vascular function in spontaneously hypertensive rats. Arterioscler. Thromb. Vasc. Biol. 58, 989-994.

Gálvez-Prieto, B., Bolbrinker, J., Stucchi, P., de Las Heras, A. I., Merino, B., Arribas, S., Ruiz-Gayo, M., Huber, M., Wehland, M., Kreutz, R., and Fernandez-Alfonso, M. S. (2008). Comparative expression analysis of the renin-angiotensin system components between white and brown perivascular adipose tissue. $J$. Endocrinol. 197, 55-64.

Gao, Y. J. (2007). Dual modulation of vascular function by perivascular adipose tissue and its potential correlation with adiposity/lipoatrophyrelated vascular dysfunction. Curr. Pharm. Des. 13, 2185-2192.

Gao, Y. J., Holloway, A. C., Zeng, Z. H., Lim, G. E., Petrik, J. J., Foster, W. G., and Lee, R. M. (2005). Prenatal exposure to nicotine causes postnatal obesity and altered perivascular adipose tissue function. Obes. Res. 13, 687-692.

Gao, Y. J., Lu, C., Su, L. Y., Sharma, A. M., and Lee, R. M. (2007). Modulation of vascular function by perivascular adipose tissue: the role of endothelium and hydrogen peroxide. $\mathrm{Br}$. $J$. Pharmacol. 151, 323-331.

Gao, Y. J., Takemori, K., Su, L. Y., An, W. S., Lu, C., Sharma, A. M., and Lee, R. M. (2006). Perivascular adipose tissue promotes vasoconstriction: the role of superoxide anion. Cardiovasc. Res. 71, 363-373.

Gil-Ortega, M., Somoza, B., Aranguez, I., Ruiz-Gayo, M., and FernándezAlfonso, M. S. (2009). Changes in resistance artery function during the development of dietinduced obesity. Hypertension 54, E105-E106.

Gil-Ortega, M., Stucchi, P., GuzmánRuiz, R., Cano, V., Arribas, S., González, M. C., Ruiz-Gayo, M., Fernández-Alfonso, M. S., and Somoza, B. (2010). Adaptative nitric oxide overproduction in perivascular adipose tissue during early diet- induced obesity. Endocrinology 151, 3299-3306.

Gollasch, M. (2012). Vasodilator signals from perivascular adipose tissue. $\mathrm{Br}$. J. Pharmacol. 165, 633-642.

Gollasch, M., and Dubrovska, G. (2004). Paracrine role for periadventitial adipose tissue in the regulation of arterial tone. Trends Pharmacol. Sci. 25, 647-653.

Gschwend, S., Pinto-Sietsma, S. J., Buikema, H., Pinto, Y. M., van Gilst, W. H., Schulz, A., de Zeeuw, D., and Kreutz, R. (2002). Impaired coronary endothelial function in a rat model of spontaneous albuminuria. Kidney Int. 62, 181-191.

Hall, J. E., Brands, M. W., Hildebrandt, D. A., Kuo, J., and Fitzgerald, S. (2000). Role of sympathetic nervous system and neuropeptides in obesity hypertension. Braz. J. Med. Biol. Res. 33, 605-618.

Kimura, K., Tsuda, K., Baba, A., Kawabe, T., Boh-oka, S., Ibata, M., Moriwaki, C., Hano, T., and Nishio, I. (2000). Involvement of nitric oxide in endothelium-dependent arterial relaxation by leptin. Biochem. Biophys. Res. Commun. 273, 745-749.

Knudson, J. D., Payne, G. A., Borbouse, L., and Tune, J. D. (2008). Leptin and mechanisms of endothelial dysfunction and cardiovascular disease. Curr. Hypertens. Rep. 10, 434-439.

Lee, R. M., Lu, C., Su, L. Y., and Gao, Y. J. (2009). Endothelium-dependent relaxation factor released by perivascular adipose tissue. J. Hypertens. 27, 782-790.

Lembo, G., Vecchione, C., Fratta, L., Marino, G., Trimarco, V., d'Amati, G., and Trimarco, B. (2000). Leptin induces direct vasodilatation through distinct endothelial mechanisms. Diabetes 49, 293-297.

Löhn, M., Dubrovska, G., Lauterbach, B., Luft, F. C., Gollasch, M., and Sharma, A. M. (2002). Periadventitial fat releases a vascular relaxing factor. FASEB J. 16, 1057-1063.

Lu, C., Su, L. Y., Lee, R. M., and Gao, Y. J. (2011). Alterations in perivascular adipose tissue structure and function in hypertension. Eur. J. Pharmacol. 656, 68-73.

Lüscher, T. F., and Vanhoutte, P. M. (1986). Endothelium-dependent contractions to acetylcholine in the aorta of the spontaneously hypertensive rat. Hypertension 8, 344-348.

Momin, A. U., Melikian, N., Shah, A. M., Grieve, D. J., Wjeatcroft, S. B., John, L., EI Gamel, A., Desai, J. B., Nelson, T., Driver, C., Sherwood, R. A., and Kearney, M. T. (2006). Leptin is an endothelial-independent vasodilator in humans with coronary artery disease: evidence for tissue specificity of leptin resistance. Eur. Heart J. 27, 2294-2299.

Payne, G. A., Borbouse, L., Kumar, S., Neeb, Z., Alloosh, M., Sturek, M., and Tune, J. D. (2010). Epicardial perivascular adipose-derived leptin exacerbates coronary endothelial dysfunction in metabolic syndrome via a protein kinase C-beta pathway. Arterioscler. Thromb. Vasc. Biol. 30, 1711-1717.

Rodriguez, A., Fortuño, A., GomezAmbrosi, J., Zalba, G., Diez, J., and Frühbeck, G. (2007). The inhibitory effect of leptin on angiotensin IIinduced vasoconstriction in vascular smooth muscle cells is mediated via a nitric oxide-dependent mechanism. Endocrinology 148, 324-331.

Rodríguez, A., Gómez-Ambrosi, J., Catalán, V., Fortuño, A., and Frühbeck, G. (2010). Leptin inhibits the proliferation of vascular smooth muscle cells induced by angiotensin II through nitric oxide-dependent mechanisms. Mediators Inflamm. 2010, 105489.

Sahin, A. S., Bariskaner, H., Gökbel, H., and Okudan, N. (2009). The dual effects of leptin on aortic rings with and without endothelium isolated from streptozotocin-induced diabetic rats. Methods Find. Exp. Clin. Pharmacol. 31, 325-329.

Schwartz, M. W., Peskind, E., Raskind, M., Boyko, E. J., and Porte, D. (1996). Cerebrospinal fluid leptin levels: plasma levels and adiposity in humans. Nat. Med. 2, 589-593.

Somoza, B., González, M. C., González, J. M., Abderrahim, F., Arribas, S. M., and Fernández-Alfonso, M. S. (2005). Modulatory role of the adventitia on noradrenaline and angiotensin II responses role of endothelium and AT2 receptors. Cardiovasc. Res. 65, 478-486.

Somoza, B., Guzmán, R., Cano, V. Merino, B., Ramos, P., DíezFernández, C., Fernández-Alfonso, M. S., and Ruiz-Gayo, M. (2007). Induction of cardiac uncoupling protein-2 expression and adenosine $\quad 5^{\prime}$-monophosphate-activated protein kinase phosphorylation during early states of diet-induced obesity in mice. Endocrinology 148, 924-931.

Vecchione, C., Maffei, A., Colella, S., Aretini, A., Poulet, R., Fratta, L., Trimarco, V., Trimarco, B., and Lembo, G. (2002). Leptin effect on endothelial nitric oxide is mediated through Akt-endothelial nitric oxide synthase phosphorylation pathway. Diabetes 51, 168-173.
Verlohren, S., Dubrovska, G., Tsang, S. Y., Essin, K., Luft, F. C., Huang, Y., and Gollasch, M. (2004). Visceral periadventitial adipose tissue regulates arterial tone of mesenteric arteries. Hypertension 44, 271-276.

Villarreal, D., Reams, G., Freeman, R., Spear, R., Tchoukina, I., and Samar, H. (2006). Leptin blockade attenuates sodium excretion in salineloaded normotensive rats. Mol. Cell. Biochem. 283, 153-157.

Wold, L. E., Relling, D. P., Duan, J., Norby, F. L., and Ren, J. (2002). Abrogated leptin-induced cardiac contractile response in ventricular myocytes under spontaneous hypertension. Role of JAK/STAT pathway. Hypertension 39, 69-74.

Zeng, Z. H., Zhang, Z. H., Luo, B. H., He, W. K., Liang, L. Y., He, C. C., and Su, C. J. (2009). The functional changes of the perivascular adipose tissue in spontaneously hypertensive rats and the effects of atorvastatin therapy. Clin. Exp. Hypertens. 31, 355-363.

Zhang, Y., Proenca, R., Maffei, M., Barone, M., Leopold, L., and Friedman, J. (1994). Positional cloning of the mouse obese gene and its human homologue. Nature 372, 425-432.

Conflict of Interest Statement: The authors declare that the research was conducted in the absence of any commercial or financial relationships that could be construed as a potential conflict of interest.

Received: 02 March 2012; paper pending published: 27 March 2012; accepted: 10 May 2012; published online: 05 June 2012.

Citation: Gálvez-Prieto B, Somoza $B$, Gil-Ortega M, García-Prieto CF, de las Heras AI, González MC, Arribas S, Aranguez I, Bolbrinker J, Kreutz R, RuizGayo $M$ and Fernández-Alfonso MS (2012) Anticontractile effect of perivascular adipose tissue and leptin are reduced in hypertension. Front. Pharmacol. 3:103. doi: 10.3389/fphar.2012.00103

This article was submitted to Frontiers in Cardiovascular and Smooth Muscle Pharmacology, a specialty of Frontiers in Pharmacology.

Copyright (c) 2012 Gálvez-Prieto, Somoza, Gil-Ortega, García-Prieto, de las Heras, González, Arribas, Aranguez, Bolbrinker, Kreutz, RuizGayo and Fernández-Alfonso. This is an open-access article distributed under the terms of the Creative Commons Attribution Non Commercial License, which permits non-commercial use, distribution, and reproduction in other forums, provided the original authors and source are credited. 